\title{
La actividad calera en las sierras de Aracena y Aroche como modeladora del territorio y de su identidad cultural
}

Javier Hernández-Ramírez | Dpto. de Antropología Social, Universidad de Sevilla Antonio Fajardo de la Fuente | Oficina del Comisionado del Polígono Sur, Consejería de Presidencia, Administración Pública e Interior Amalia Tarín Alcalá-Zamora | Secretaría General de Infraestructuras, Movilidad y Ordenación del Territorio, Consejería de Fomento, Infraestructuras y Ordenación del Territorio

URL de la contribución <www.iaph.es/revistaph/index.php/revistaph/article/view/4685>

\section{RESUMEN}

Este artículo pone de manifiesto el papel que representa la producción de cal en la configuración del paisaje cultural de las sierras de Aracena y Aroche (Huelva), resaltando su potencial como una actividad con interesantes perspectivas de futuro. Muestra la continuidad histórica de la producción de cal en la zona -utilizada tanto para la obtención de mortero como para enjalbegar paredes- y aporta un inventario de los principales grupos de hornos de cal y otras instalaciones afines dispersas por el territorio. El estudio revela que el uso y producción de cal es visible hoy en la singular arquitectura vernácula de los pueblos y del medio rural de la sierra. Asimismo, el artículo pretende sensibilizar sobre la interrupción de la producción de cal, que pone en peligro unos modelos constructivos únicos e incrementa el riesgo de incendios. El artículo concluye señalando que la valorización del patrimonio cultural vinculado a la producción de cal puede ralentizar esta dinámica regresiva, actuando como un vehículo para impulsar innovadoras iniciativas socioeconómicas.

\section{Palabras clave}

Actividades tradicionales | Arquitectura vernácula | Hornos de cal | Paisaje cultural | Patrimonio etnológico | Sierras de Aracena y Aroche (Huelva) | 


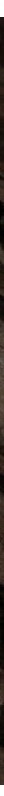

\section{The production of lime in the sierras de Aracena y Aroche and its role in shaping the area's cultural landscape}

\section{ABSTRACT}

This paper discusses the role played by the production of lime in the conformation of the cultural landscape of the sierras de Aracena y Aroche (Huelva), highlighting its potential as an activity with interesting future prospects. It demonstrates the historical continuity of the production of lime in the area -being used for making mortar and for whitewashing walls- and it provides an inventory of the main groups of lime kilns and other related facilities spread throughout the territory. This study reveals that the use and production of lime is visible today in the unique vernacular architecture of the hill towns and the rural environment of the Sierra. At the same time, this paper also aims to raise awareness about the discontinuity of lime production, which jeopardizes the area's unique building patterns and increases the risk of wildfires. The paper concludes by pointing out that the valorisation of the cultural heritage embodied in the culture of lime making can slow down this regressive dynamic, acting as a vehicle for far-reaching and innovative socioeconomic initiatives.

\section{Keywords}

Traditional activity | Vernacular architecture | Lime kilns | Cultural landscape | Ethnological heritage | Sierras de Aracena y Aroche (Huelva) |

Cómo citar: Hernández-Ramírez, J., Fajardo de la Fuente, A. y Tarín Alcalá-Zamora, A. (2021) La actividad calera en las sierras de Aracena y Aroche como modeladora del territorio y de su identidad cultural. revista $P H$, n. ${ }^{\circ}$ 102, pp. 20-39. Disponible en: www.iaph.es/revistaph/index.php/revistaph/article/view/4685 DOI 10.33349/2021.102.4685

Enviado: 19/05/2020 | Aceptado: 23/11/2020 | Publicado: 10/02/2021 


\section{INTRODUCCIÓN. OBJETIVOS, METODOLOGÍA Y ALCANCE}

La actividad calera en las sierras de Aracena y Aroche (Huelva) se encuadra dentro de una sociedad tradicional cuya existencia se apoyaba en la extracción y transformación de los recursos naturales presentes en su entorno. En este modo de vida campesino, el medio ambiente circundante constituía la principal fuente de abastecimiento de energía, alimentos y materias primas indispensables para asegurar la continuidad de la comunidad. Es dentro de este marco en el que se sitúa la actividad calera, la cual debe ser entendida como una singular adaptación de esta sociedad a las condiciones ambientales del territorio. La extracción de la roca caliza de los cerros para la producción de cal, ya fuera para elaborar mortero o para enjalbegar (encalar) paredes y muros, tras su cocción en hornos, suponía un modo de apropiación de la naturaleza basado en la transformación de recursos autóctonos. De toda esta tradición hoy solo nos queda la memoria del oficio, que atesoran los antiguos caleros, y los propios hornos como estructuras presentes en la geografía de la sierra, que testimonian un modo de vida concluido hace escasas décadas.

1

En este trabajo se emplea el término patrimonio etnológico de acuerdo con la definición contenida en la vigente Ley $14 / 2007$, de 26 de noviembre, del Patrimonio Histórico de Andalucía: "Son bienes integrantes del Patrimonio Etnológico Andaluz los parajes, espacios, construcciones o instalaciones vinculados a formas de vida, cultura, actividades y modos de producción propios de la comunidad de Andalucía" (Título Vl, artículo 61).
La valorización del patrimonio cultural que representa la actividad calera como elemento del pasado con potencialidad para el futuro constituye el objetivo fundamental de este trabajo. Para alcanzarlo, nos proponemos cubrir cuatro objetivos subordinados al mencionado anteriormente. En primer lugar, ampliar la información histórica existente sobre esta actividad en las sierras de Aracena y Aroche. En segundo, identificar cartográficamente e inventariar las instalaciones horneras presentes en la actualidad. En tercero, resaltar que la actividad calera ha contribuido decisivamente a la conformación del paisaje cultural serrano, favoreciendo la protección ambiental y el manejo tradicional de las actividades y modelando una arquitectura vernácula serrana muy singular. Y, por último, destacar la potencialidad de este patrimonio etnológico para el impulso de proyectos audaces e innovadores ${ }^{1}$.

Para alcanzar los objetivos señalados se ha procedido a utilizar una metodología mixta, que combina el estudio de fuentes bibliográficas, documentales y cartográficas con el trabajo de campo etnográfico. Para rastrear los orígenes y la implantación de la actividad, se ha consultado la información histórica publicada sobre la cal en la sierra y, con el objetivo de conocer el oficio, la investigación se ha apoyado en entrevistas realizadas a caleros y vecinos. La conjugación de las informaciones procedentes de las fuentes escritas con las orales ha permitido profundizar en el conocimiento del oficio, la localización de las zonas caleras y la influencia cultural de la actividad a lo largo de la historia.

La investigación concluye subrayando que los hornos de cal y la memoria del oficio testimonian la existencia de una actividad muy arraigada durante siglos en la comarca. Culturas del trabajo e instalaciones, es decir, cultura 
inmaterial y material forman parte de un rico patrimonio etnológico que ha dejado su huella en el paisaje cultural serrano. Asimismo, se señala que la valorización de la cultura de la cal puede funcionar en la actualidad como un motor de iniciativas tales como la renovación del caserío serrano autóctono y la dinamización de un modelo turístico sostenible de base local.

\section{EVOLUCIÓN Y TRASCENDENCIA DE LA ACTIVIDAD CALERA EN LA SIERRA}

En este apartado analizaremos la evolución histórica de la actividad calera, acrecentando los conocimientos existentes sobre la misma. Anteriores estudios se aproximan a la historia, sistemas de producción, tipología de hornos, organización del trabajo y memoria colectiva de esta actividad en el pequeño municipio de Santa Ana la Real (Lijó y Monge Manso 1999; Monge Manso 2005, 2007; Hernández-Ramírez 2005, 2007, 2011). Con este artículo se desea continuar la senda iniciada por estas investigaciones, resaltando que dicha actividad también se ha materializado en otras localidades de la sierra, aunque no con el mismo grado de concentración.

La elaboración de la cal viva y la producción de morteros y cal blanca albergan una serie de técnicas artesanales que entroncan con una tradición milenaria extendida por todo el arco mediterráneo. Desde sus orígenes en tiempos remotos, se han transmitido de generación en generación por toda esta amplia área cultural los conocimientos de un oficio cuyas técnicas esenciales han continuado sin grandes modificaciones hasta principios de los años sesenta del siglo XX, en los que prácticamente desaparece ante la expansión y popularización del cemento y las pinturas plásticas (Herrero Núñez 2005).

Llama la atención que, en términos generales, los métodos de producción y los tipos de hornos expuestos por escritores de la Antigüedad (Catón y Vitruvio) coinciden con los existentes en la sierra, lo que relaciona a la comarca con una larga tradición artesana. Ello nos lleva a considerar la actividad calera de las sierras de Aracena y Aroche como un exponente de una cultura artesana-industrial mediterránea que tiene su origen en la Antigüedad, siendo los hornos un significativo testimonio material de este oficio milenario. Esta circunstancia justifica, ya de por sí, la protección y valorización tanto de los hornos como de la memoria aún viva del oficio.

\section{Los borrosos orígenes de la actividad}

Los comienzos de la actividad calera en la sierra son poco conocidos. Nuestra fuente más antigua ha sido Las Respuestas Generales del Catastro del Marqués de la Ensenada (1750-54), que constituyen una excelente radiografía de la situación de las sierras de Aracena y Aroche al final del Antiguo 
2

Tan solo existe una mención a la extracción de minerales en Cañaveral de León con los que se elaboraban "panes de oro y plata".
Régimen. En ellas se indica que la actividad agraria es la principal base económica y que las industrias existentes se derivan de la misma (molinos harineros, almazaras, lagares, batanes y calderas para sacar aguardiente). Sin embargo, no existe ninguna referencia a la producción de cal viva y son muy escasas las menciones a otras actividades manufactureras, mineras y extractivas que necesariamente tenían que existir ${ }^{2}$.

Una fuente que quizá hubiera clarificado algo más el origen de la actividad son las Relaciones enviadas por los párrocos al geógrafo real Tomás López entre 1786 y 1796 (Ruiz González 1999). Lamentablemente, el documento solo cuenta con capítulos referidos a doce poblaciones y está incompleto. En estas relaciones tampoco existen alusiones explícitas a la actividad calera, aunque sí se mencionan algunas informaciones, como la presencia de canteras de mármol prieto y jaspe blanco, que nos permiten deducir la producción de cal.

Tampoco aparecen datos directos sobre los hornos de cal en el Diccionario Histórico-Geográfico-Estadístico de España y sus posesiones de Ultramar de Pascual Madoz, de 1845-50. El Diccionario presenta una comarca donde el comercio, la producción en molinos hidráulicos y la actividad minera ocupaban a muchos de sus vecinos. Sin embargo, no hay alusiones directas a la producción de morteros y cal blanca, aunque se reseñan las canteras de mármol y jaspe de Aracena y las de mármol en Aroche y Fuenteheridos, pero para indicar que su explotación no se realizaba o que estaba muy condicionada por el mal estado de los caminos.

Particularizando el análisis al municipio mejor conocido (Santa Ana la Real), la primera fuente documental que refleja fehacientemente la actividad calera es de 1899. Corresponde a un mapa perteneciente a la serie Bosquejos planimétricos por términos municipales en el que se detalla el emplazamiento de una serie de hornos en la zona norte del municipio, concretamente en las laderas de las sierras de Los Palos Altos y las Cumbres de la Serrachuela y en las inmediaciones de la vereda de Castaño del Robledo.

La cuestión a esclarecer es si la actividad se implanta inicialmente a finales del XIX, como prueba este mapa, o si anteriormente ya existía tradición calera en la localidad. El análisis del patrimonio edilicio monumental y de la arquitectura vernácula deja en evidencia que hasta mediados del siglo XX no se introduce de forma significativa otro mortero que sustituya al tradicional compuesto por cal, arena y agua. Por otro lado, factores tales como el relativo aislamiento de la sierra durante el Antiguo Régimen, la economía campesina de subsistencia, la existencia de zonas boscosas y la presencia de canteras de mármoles y calizas hacen presuponer que las poblaciones serranas elaboraban y se abastecían de la cal producida en sus propios hornos para la construcción de sus viviendas e instalaciones agropecuarias. 
Muy probablemente estos trabajos no constituían un oficio especializado, sino que se realizaban a pequeña escala como una actividad complementaria orientada al autoconsumo y a un exiguo mercado. Quizás por ello no existan referencias en la documentación histórica.

En este contexto de economía campesina es probable que la cal viva escapara de la lógica de la economía monetaria y que su comercialización se basara en otros sistemas de intercambio, como el trueque, dentro de un reducido ámbito comarcal. Fortalece esta hipótesis el hecho de que las fuentes históricas señaladas anteriormente son, en realidad, padrones que recogen actividades económicas con fines exclusivamente fiscales y de recaudación para contribuir a las arcas del Estado. Sea como fuere, hasta la segunda mitad del siglo XVIII la producción de cal viva debió de ser reducida ante una escasa demanda. Así se deduce del hecho de que en las Respuestas Generales los oficios ligados a la construcción apenas aparecen representados, y rara era la localidad de la sierra que contara con más de dos maestros u oficiales albañiles, siendo más significativa la presencia de otros oficios como herreros, zapateros, cerrajeros o carpinteros. Esta presencia testimonial parece indicar además el importante peso de la autoconstrucción en la arquitectura tradicional serrana.

\section{Despegue y apogeo}

Es muy probable que la elaboración de cal viva experimentara un considerable crecimiento a partir del último cuarto del siglo XVIII, pues esta etapa inaugura un nuevo periodo de prosperidad en toda la sierra en el que se vive una intensificación económica y un importante crecimiento demográfico. Esto se tradujo en la colonización de nuevos espacios, en la extensión del castañar que había empezado a sustituir a los robledales desde el siglo XVI, en el aumento de la actividad constructora de viviendas y en la edificación de nuevos y monumentales templos parroquiales que reemplazaron a los dañados por el terremoto de Lisboa (Fajardo de la Fuente y Tarín Alcalá-Zamora 2004). Este dinamismo debió de suponer un incremento de la producción de cal; no obstante, como decíamos, las fuentes documentales no clarifican este extremo.

Durante toda la segunda mitad del XIX, el desarrollo de la minería a cielo abierto bajo sistemas de explotación típicamente capitalistas, así como la progresiva implantación de una red ferroviaria que conectaba distintos asentamientos mineros tras la construcción de la línea Zafra-Huelva en 1889, supusieron un impulso a la actividad calera, que pasó de ser una base económica residual a una fuente de ingresos fundamental de algunos sectores. A finales del siglo XIX, una serie de municipios serranos vecinos como Santa Ana la Real, Almonaster la Real, Cortegana y otros de la cercana Cuenca del Río Tinto vivieron un notable impulso económico y demográfico ligado a su desarrollo minero, que se tradujo en la ampliación de las explotaciones exis- 
Así lo explicaba un antiguo cargador: "Antes se cocían dos hornadas al año y más tarde con las minas se hacían veinte. Los hornos no paraban y teníamos vendida la cal dos meses antes de hacerla. Había mucha guilla" (Hernández-Ramírez 2011). tentes, la inauguración de nuevas concesiones y la aparición de numerosos poblados mineros (Núñez Laso de la Vega 1999). Según cuentan los caleros más viejos, sus abuelos les comentaron que los nuevos enclaves demandaban mortero para la construcción y que, desde entonces, la producción de cal viva pasó de ser una actividad complementaria de autoconsumo a una especialización productiva orientada al mercado exterior, que abastecía tanto a los nuevos poblados mineros, cuyo parque de viviendas e instalaciones crecía rápidamente, como a otras localidades serranas.

El aumento de la demanda impulsó una serie de transformaciones: se generalizaron determinadas innovaciones tecnológicas, como el uso del fogón o el empleo de dinamita para la extracción de la caliza, que contribuyeron a aumentar la producción y la eficiencia de los hornos; cambió el sistema de comercialización del producto, que en pocos años adquirió una considerable envergadura tanto por la aparición de intermediarios, que establecían contratos entre las minas y los caleros, como por el empleo de nuevos medios de transporte (camiones, ferrocarril) y comunicaciones (carreteras y vías férreas), que permitieron trasladar más rápidamente el producto a destinos más alejados y que poco a poco fueron sustituyendo a los tradicionales arrieros. A esta expansión del sector calero contribuyeron también las repoblaciones forestales, que hicieron más fácil y económica la obtención del combustible necesario para practicar hornadas.

La crisis minera del pasado siglo debió de afectar negativamente a la producción de cal viva. Sin embargo, la especialización de algunas localidades en una actividad que abastecía de esta materia prima básica a toda la comarca contribuyó a mitigar la pobreza, especialmente en los años de la posguerra civil. Esta situación contrastaba con algunos pueblos vecinos cuya orientación agropecuaria, desigual estructura de la propiedad y bajos salarios se tradujeron en unas duras condiciones de existencia y pocas alternativas económicas (Collier 2009).

Por los testimonios recabados, hasta los sesenta, la actividad calera fue significativa en Santa Ana la Real, Fuenteheridos, Cañaveral de León y Aroche, teniendo una presencia más difusa en el resto de la comarca. Durante los meses de verano sobre todo, los humos expelidos por los hornos, el estruendo de las voladuras, el sonido repetitivo de marras y barrenas en las pedreras, el ir y venir de los burros con sus cargas de leña, la entrada y salida de camiones cargados de cal viva..., todo, en suma, estaba presidido por un ambiente de actividad que marcaba el ritmo cotidiano y la imagen de los pueblos caleros ${ }^{3}$.

\section{La crisis terminal de la producción calera}

La producción de mortero de cal declinó rápidamente a fines de los sesenta del pasado siglo. Dos factores fundamentales explican esta crisis terminal: 


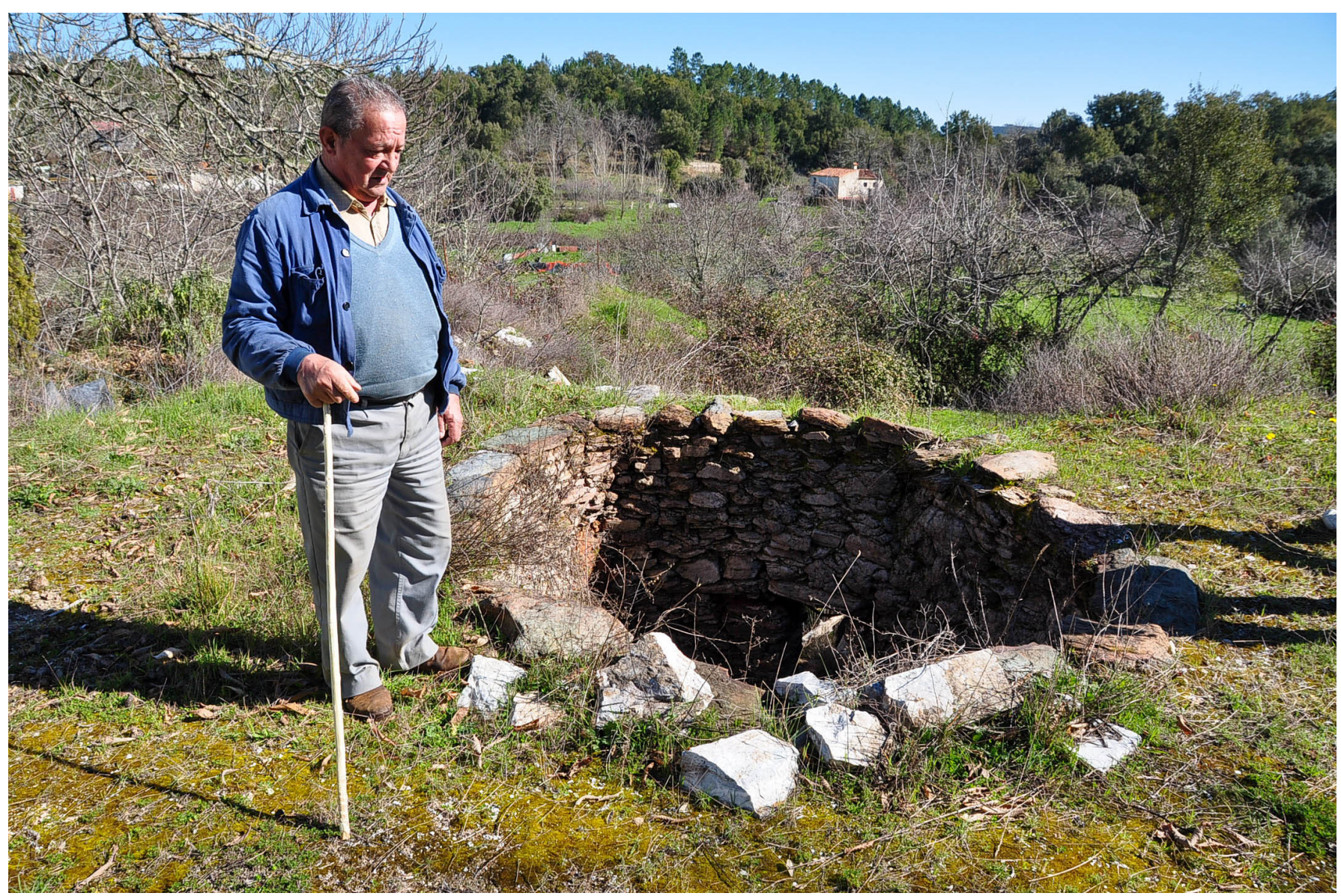

Guillermo, último calero de Fuenteheridos, en su horno en desuso del paraje de las canteras del

de un lado, la generalización y popularización de los productos industriales Cerro Blanco (2014) | foto Amalia Tarín Alcalá(el cemento, como aglomerante más económico y menos laborioso en su ejecución que la argamasa, y las pinturas plásticas, más resistentes y duraderas que la cal blanca); y, de otro, el mantenimiento de un tipo de horno artesanal incapaz de competir con los industriales, más eficientes, que se iban instalando en otras localidades. Ambos factores supusieron la desaparición definitiva de una actividad tradicional anclada en la historia. Las biografías de los caleros recogidas durante el trabajo de campo muestran el drama personal de muchos de ellos que contemplaron el fin de su oficio, sin encontrar trabajos alternativos que pudieran reemplazarlo. La consecuencia fue la emigración de la mayoría, sobre todo a Cataluña y Europa.

La producción de cal blanca perduró algunas décadas más que la del mortero, pues la competencia con la pintura plástica no se agudizó hasta la última década del pasado siglo. De hecho, los gritos del calero pregonando por las calles: " $C$ Cal en piedra!" fueron relativamente comumes hasta hace pocos años en muchos municipios, lo que permanece muy vivo en la memo- 


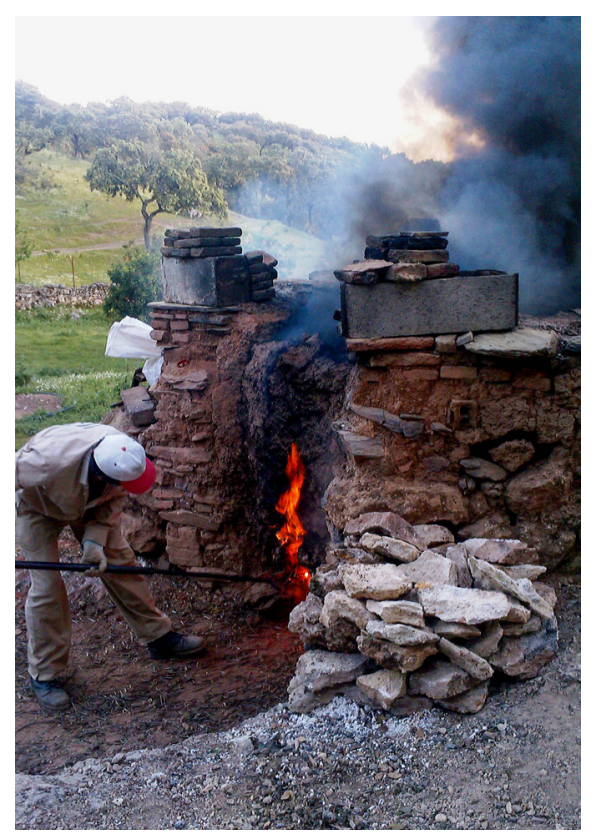

El horno de Julián, aún en uso, en Cañaveral de León (2014) | foto Joaquín Hernández de la Obra

4

Destacan las formaciones travertínicas (Alájar, Zufre e Higuera), las cuevas (Aracena, Cañaveral, Galaroza, Alájar y Cuevas de la Mora) y los campos de lapiaces (Aracena) (Garrido y Romero 2004).

5

Concretamente, al norte del término municipal de Fuenteheridos se emplaza un importante conjunto de canteras (La Herradura, Nava Longuilla, Alto del Carmen y sobre todo Cerro Blanco) que destacan por su explotación continuada, hoy abandonada.

6

Para la representación de estos elementos la escala apropiada es la 1:10.000 ria colectiva de los mayores. Pero, poco a poco, los hornos se fueron apagando. En Fuenteheridos y Aroche las llamas de las hornadas eran todavía visibles a principios del presente siglo, cesando definitivamente la actividad hacia 2003-2004. En la actualidad, el único testimonio vivo y activo es el de Julián, un vecino de Cañaveral de León hijo de calero, que mantiene el oficio como una actividad a tiempo parcial y sin que corra de momento peligro de abandono.

\section{DISTRIBUCIÓN DE LOS HORNOS DE CAL EN LA COMARCA}

La comarca se engloba casi en su totalidad en la unidad Ossa-Morena, caracterizada por su complejidad tectónica y petrológica. Sin duda una de las formas más características de este relieve, junto con los granitos de Santa Olalla, es el modelado kárstico ${ }^{4}$. En el sector central se manifiestan con continuidad las rocas carbonatadas, puntualmente cristalizadas por acciones metamórficas, formando los mármoles, que encuentran en Fuenteheridos y Aroche las principales zonas de explotación ${ }^{5}$. La actividad calera se sustenta en la existencia de abundante materia prima: rocas calizas y mármoles. Esta riqueza es el resultado de complejos fenómenos geológicos de compresión y descompresión de los materiales de la corteza terrestre que dieron lugar a variadas mineralizaciones (Carrero Carrero 1997).

El análisis realizado para este estudio de la primera serie del Mapa Topográfico Nacional (MTN) (1946 y 1955) permite asegurar que esta riqueza de piedra caliza ha sido explotada por la actividad calera. No obstante, el número de hornos cartografiados por esta serie es solo de nueve, a pesar de que en estos años la actividad calera estaba en pleno apogeo. Esto podría ser debido a que la recogida de datos sobre el terreno para la elaboración del mapa no siguiera criterios homogéneos o a que la escala del MTN no sea la más adecuada para la representación de este tipo de instalaciones, por lo que estimamos que el número debía de ser mayor que el representado ${ }^{6}$.

La toponimia es también un indicador de la extensión e importancia de la actividad calera en la sierra. Se ha realizado una búsqueda selectiva de topónimos incluidos en el Nomenclátor Geográfico de Andalucía, examinando aquellas referencias que incluyesen los términos "horno" y "cal". Como resultado de la pesquisa se han identificado 39 topónimos correspondientes a elevaciones (por ejemplo, Alto de la Caldera y Cabezo del Calar), cursos fluviales (Barranco de la Caldera), parajes (Los Calares) y lugares habitados (Cortijo de los Hornos), repartidos por toda la comarca. Aunque no todos los topónimos reconocidos están necesariamente vinculados con la actividad calera, el elevado número hallado es un indicio más de la longeva tradición hornera en la sierra. 


\begin{tabular}{|ll}
\hline Lugar, topónimo & Término municipal \\
\hline La Silladilla & Jabugo \\
\hline Cantera & Aracena \\
\hline Las Lagunillas & Encinasola \\
\hline Dehesa del Campillo & Encinasola \\
\hline Casa del Campillo Alto & Cumbres de San Bartolomé \\
\hline La Venta & Aroche \\
\hline Horno de Pupo & Rosal de la Frontera \\
\hline Cerro Parrales & Zufre \\
\hline Cortijo El Tejar & Higuera de la Sierra \\
\hline
\end{tabular}

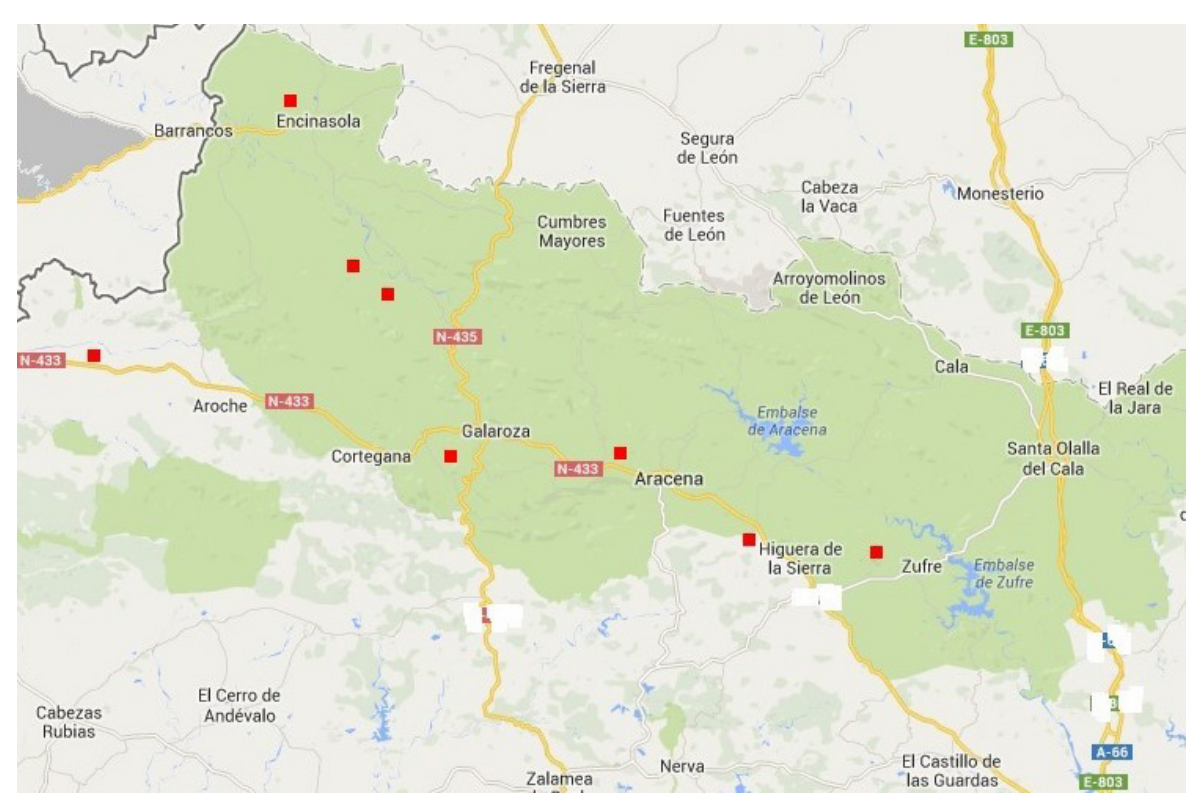

Gracias a la información encontrada en distintas fuentes y, sobre todo, al trabajo de campo realizado para este estudio, sabemos que en la comarca se localizan restos de más de 80 hornos, de los cuales 29 están georre-

Distribución de hornos en la primera serie del MTN 1:50.000 (1946-1955) | fuente Elaboración propia a partir del análisis de las hojas del MTN n 874.

875, 894, 895, 896, 897, 915, 916, 917, 918, 919, 937, 938,939 y 940 . Instituto Geográfico Nacional (1918-1955) 
Hornos caleros localizados y principales focos productivos | fuente Elaboración propia
Localización de los hornos de cal en la Sierra de Aracena y Aroche (excluidos los de Santa Ana la Real)* | fuente Trabajo de campo. Sistema de referencia ETRS 89, Huso 29. Elaboración propia. *No se incluyen los hornos localizados en Santa Ana la Real, ya inventariados en HernándezRamírez 2011

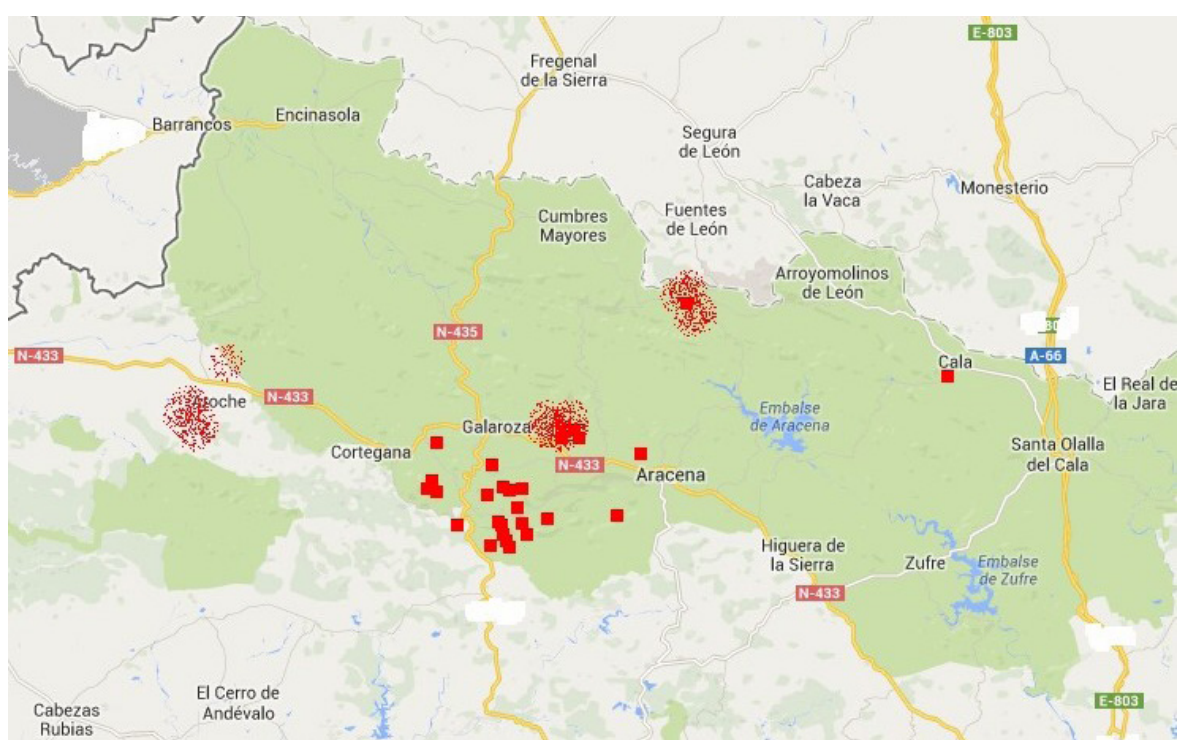

\begin{tabular}{|c|c|c|c|}
\hline Localización, denominación & Coordenadas X & Coordenadas Y & Estado \\
\hline Sierra de la Chau. Alájar & $37^{\circ} 57^{\prime} 27.45^{\prime \prime} \mathrm{N}$ & $6^{\circ} 38^{\prime} 56.54^{\prime \prime} \mathrm{W}$ & Abandono \\
\hline Finca de la Horra I. Almonaster la Real & $37^{\circ} 52^{\prime} 30.96^{\prime \prime} \mathrm{N}$ & $6^{\circ} 46^{\prime} 56.26^{\prime \prime} \mathrm{W}$ & Abandono \\
\hline Finca de la Horra II. Almonaster la Real & $37^{\circ} 52^{\prime} 31.96 " N$ & $6^{\circ} 46^{\prime} 56.80^{\prime \prime} \mathrm{W}$ & Deficiente \\
\hline Finca de la Horra III. Almonaster la Real & $37^{\circ} 52^{\prime} 32.13^{\prime \prime} \mathrm{N}$ & $6^{\circ} 47^{\prime} 3.72^{\prime \prime} \mathrm{W}$ & Deficiente \\
\hline Calerín Finca de la Horra. Almonaster & $37^{\circ} 52^{\prime} 31.18^{\prime \prime} \mathrm{N}$ & $6^{\circ} 46^{\prime} 58.17 " \mathrm{~W}$ & Bueno \\
\hline Casas del Pelete. Aracena & $37^{\circ} 53^{\prime} 45.03^{\prime \prime} \mathrm{N}$ & $6^{\circ} 34^{\prime} 59.66^{\prime \prime} \mathrm{W}$ & Bueno \\
\hline Horno de Julián. Cañaveral de León & $38^{\circ} 00^{\prime} 58.63^{\prime \prime} \mathrm{N}$ & $6^{\circ} 32^{\prime} 43.99 " W$ & En uso \\
\hline El Torvisco. Cala & $37^{\circ} 58^{\prime} 54.79^{\prime \prime} \mathrm{N}$ & $6^{\circ} 19^{\prime} 55.64 " \mathrm{~W}$ & Abandono \\
\hline Paraje del Agrión. Fuenteheridos & $37^{\circ} 55^{\prime} 3.45^{\prime \prime} \mathrm{N}$ & $6^{\circ} 40^{\prime} 3.49^{\prime \prime} \mathrm{W}$ & Bueno \\
\hline Horno de Guillermo 1. Fuenteheridos & $37^{\circ} 55^{\prime} 11.00^{\prime \prime} \mathrm{N}$ & $6^{\circ} 39^{\prime} 55.57 " \mathrm{~W}$ & Bueno \\
\hline Horno de Guillermo 2. Fuenteheridos & $37^{\circ} 55^{\prime} 11.71^{\prime \prime} \mathrm{N}$ & $6^{\circ} 39^{\prime} 56.65^{\prime \prime} \mathrm{W}$ & Bueno \\
\hline Los Calares. Jabugo & $37^{\circ} 54^{\prime} 0.72^{\prime \prime} \mathrm{N}$ & $6^{\circ} 43^{\prime} 24.42^{\prime \prime} \mathrm{W}$ & Deficiente \\
\hline Rojabugo. Jabugo & $37^{\circ} 55^{\prime} 39.28^{\prime \prime} \mathrm{N}$ & $6^{\circ} 43^{\prime} 58.41 " W$ & Deficiente \\
\hline
\end{tabular}

En las tablas se relacionan la distribución por municipios de los hornos, sus coordenadas y estado de conservación.

Los hornos inventariados se ajustan a la tipología artesanal. Se caracterizan por permitir un sistema de producción semi-continuo basado en el trabajo manual y en técnicas heredadas de la tradición. Son denominados "de llama larga", porque el combustible empleado para las hornadas debe ser de pequeñas dimensiones y muy seco para así producir un calor intenso y llamas copiosas. Aunque sus dimensiones son variables, todos ellos son semejantes en cuanto a sus características estructurales: planta circular, forma troncocónica e interior hueco (Hernández-Ramírez 2011). 


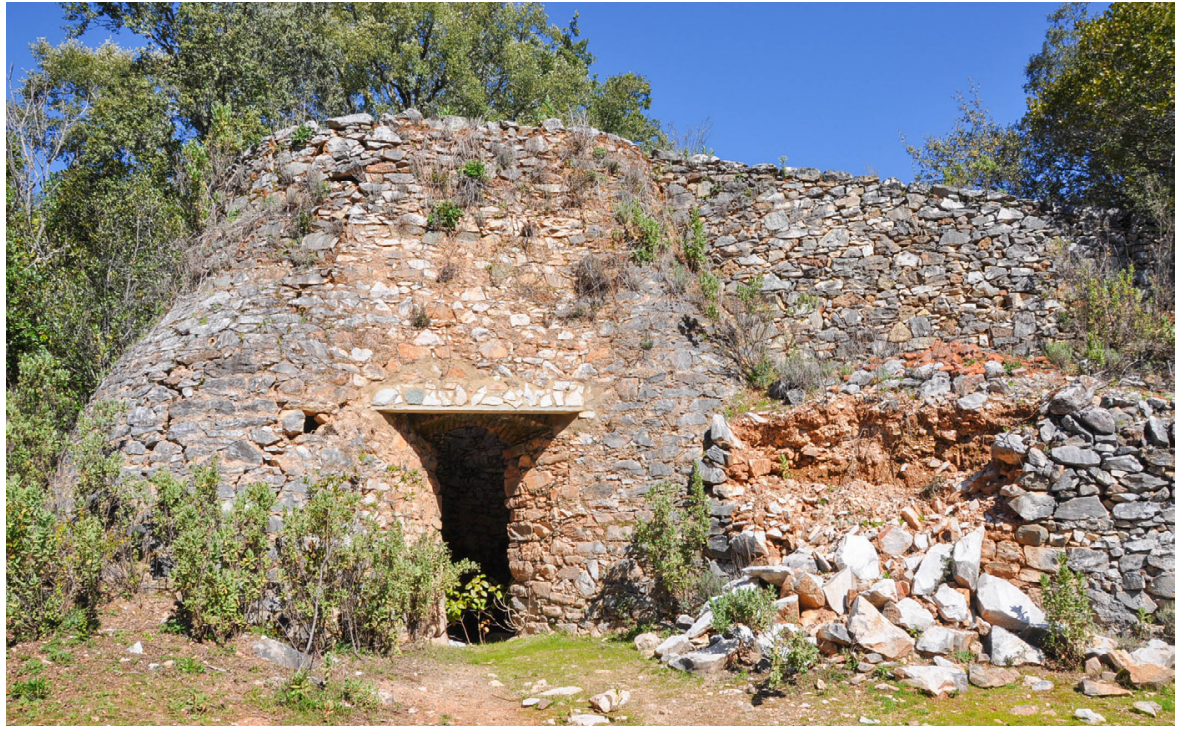

Horno del paraje del Agrión (Fuenteheridos) (2014) | foto Amalia Tarín Alcalá-Zamora

\begin{tabular}{|c|c|c|c|c|}
\hline Municipio & $\begin{array}{l}\text { n. }{ }^{\circ} \text { hornos existen- } \\
\text { tes, por referencias }\end{array}$ & $\begin{array}{l}\text { n. }{ }^{\circ} \text { de hornos } \\
\text { localizados }\end{array}$ & Comentarios & Fuente \\
\hline Alájar & 6 & 1 & Cal prieta & Informante local \\
\hline Almonaster la Real & 4 & 4 & & $\begin{array}{l}\text { Carta etnológica del tér- } \\
\text { mino municipal (2012) }\end{array}$ \\
\hline Aracena & Varios & 1 & Cal blanca, hornos recientes (siglo XX) & Informante local \\
\hline Aroche & Al menos 10 & 0 & $\begin{array}{l}\text { Cal prieta y blanca, comercializada en Aroche y } \\
\text { Cortegana. Activos hasta } 2003\end{array}$ & Informante local \\
\hline
\end{tabular}

Cal blanca comercializada por el norte de la

Cañaveral de León Varias decenas
comarca y sur de Extremadura. Horno en activo. Varios hornos destruidos recientemente en las Informante local proximidades de la población

\begin{tabular}{|c|c|c|c|c|}
\hline Cala & Al menos 2 & 1 & & Informante local \\
\hline Fuenteheridos & Cerca de 20 & 3 & $\begin{array}{l}\text { Cal blanca, de gran prestigio. Tradición hornera } \\
\text { de varias generaciones Comercializada hasta } \\
2004 \text { por toda la comarca. Hornos de grandes } \\
\text { dimensiones }\end{array}$ & Informante local \\
\hline Jabugo & Al menos 2 & 2 & & Informante local \\
\hline Total & Más de 80 & 29 & & \\
\hline
\end{tabular}

Distribución de los hornos de cal localizados o referenciados por municipios | fuente Elaboración propia 

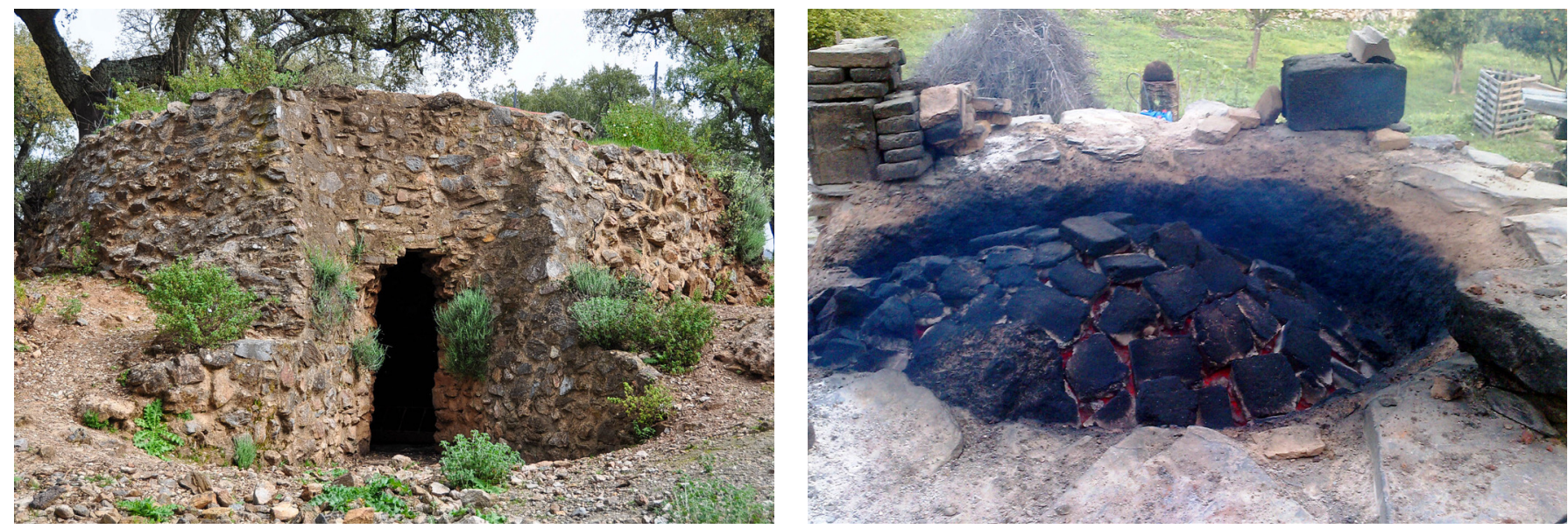

A la izquierda, horno de Puerto Molino (Santa Ana la Real) (2014) | foto Amalia Tarín Alcalá-Zamora

\section{LA CAL, MODELADORA DEL PAISAJE SERRANO}

A la derecha, horno de Julián (Cañaveral de León) (2014) | foto Joaquín Hernández de la Obra

La actividad de desbroce para la obtención de combustible no era en absoluto anecdótica, ya que -tal como relatan los antiguos caleros de Santa Ana la Real- en los hornos más especializados cada hornada exigía el uso de entre 10 y 14 toneladas de leña, prefiriéndose la de matorral (brezo, aulaga, jara), por su mayor poder calórico.

8

Solo entre 1956 y 2007 en el Parque Natural se ha producido un retroceso del $17 \%$ de los usos agrícolas, del $28 \%$ del pastizal arbolado, del $36 \%$ del matorral arbolado y del $46 \%$ de pastizal; por el contrario, ha habido un aumento del $20 \%$ de los usos forestales y de un 36 \% del matorral, según la Red de Información Ambiental de Andalucía.

\section{La integración de la actividad calera en el sistema agro-silvo-pastoril}

La actividad calera se encontraba en estrecha relación con el resto del sistema de aprovechamiento tradicional. Los campesinos usaban la arboleda y el matorral desbrozado, especialmente la jara (Carrero Carrero 1995), como principal fuente de energía doméstica, reservando parte como combustible para las hornadas que realizarían en verano, lo que favorecía, además, la explotación ganadera en las dehesas ${ }^{7}$.

Este uso diversificado del bosque revela la armónica relación existente entre las distintas actividades de la economía campesina y la integración de la calera en las mismas, lo que se traducía en un efecto beneficioso sobre el medio, ya que la roza regeneraba el suelo forestal y reducía el riesgo de incendios, mostrando un claro ejemplo de interdependencia y complementariedad. Por todo ello, la limpieza del monte no solo funcionaba como un recurso económico directo para las hornadas, sino también como una estrategia que perseguía optimizar el aprovechamiento silvo-pastoril y un mejor manejo del monte.

La extinción de la actividad calera coincidió en el tiempo con el proceso de abandono del conocido como "bosque habitado", perceptible en las frías estadísticas $^{8}$, y a través de la comparación de las imágenes aéreas de los últimos 60 años. Concretamente en Santa Ana la Real, la extinción de la actividad hornera ha tenido consecuencias muy negativas para el medio ambiente. Las fotografías reflejan la evolución de los usos del suelo en el sitio llamado El Barranco del Hornillo, situado en su término municipal. En ellas se aprecia con claridad el aumento de la superficie forestal y el retroceso de los espacios mixtos de aprovechamiento campesino (pastizal-mato- 

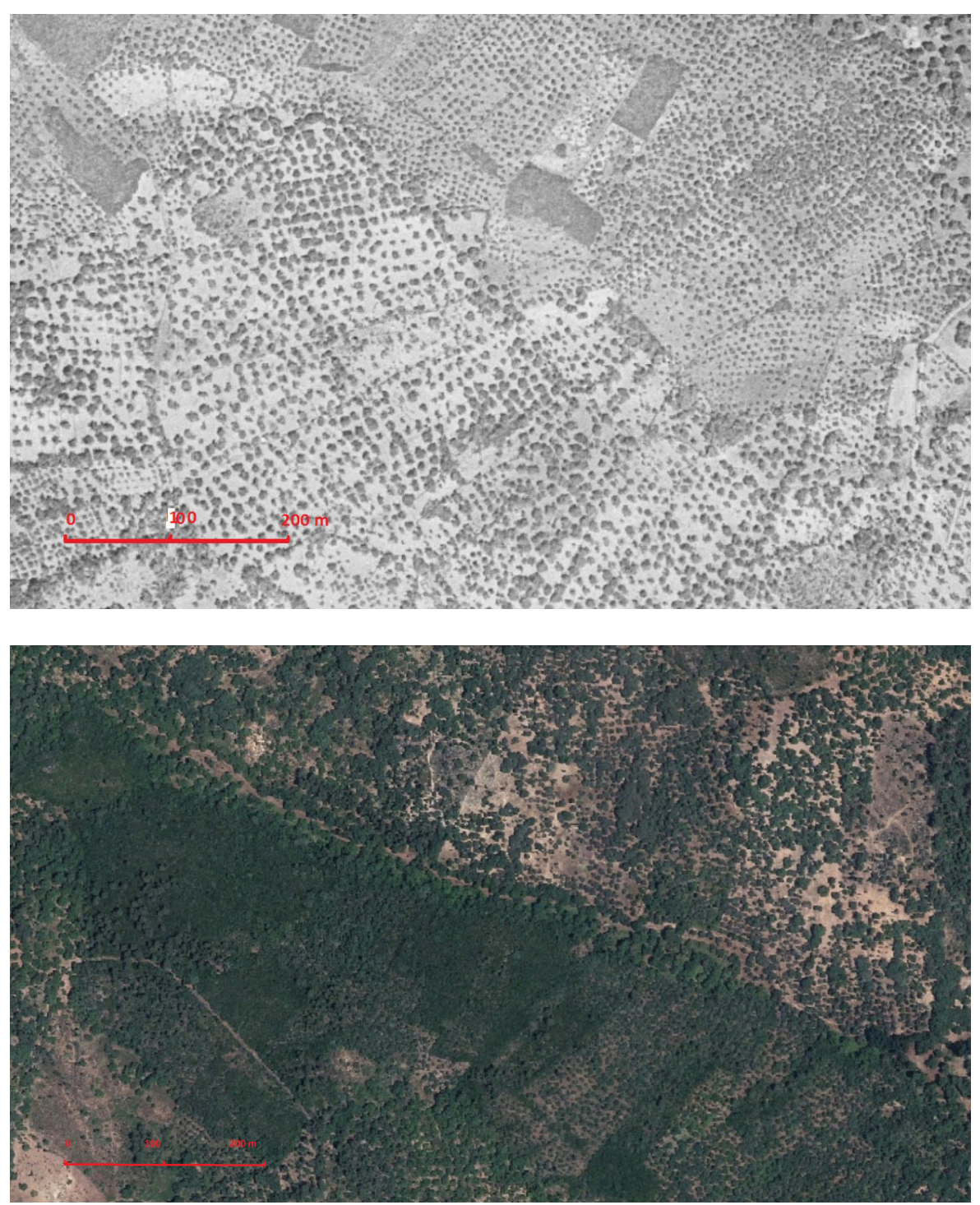

rral, policultivo de autosuficiencia, ganadería) sufrido desde mediados de los cincuenta hasta nuestros días.

Las imágenes revelan que la desaparición de los usos tradicionales forestales y agropecuarios, y muy especialmente de las rozas para alimentar los hornos de cal, tiene consecuencias directas sobre el territorio, que pierde diversidad y parte de sus funciones de alimentación del ganado, al dificultarse el pastoreo. En este contexto, el riesgo de fuegos forestales ha crecido notablemente ante la práctica desaparición de las labores de desbroce y la consecuente sobrecarga de combustible vegetal. Prueba de ello es que en las dos últimas décadas se han sucedido importantes incendios forestales en zonas caleras ${ }^{9}$.
Evolución de usos del suelo en la zona hornera del Barranco del Hornillo, 1956, Santa Ana la Real fuente Ortofotografía del Vuelo Americano de la Serie B. 1956-57. USAF. Ministerio de Defensa. Tomada a escala 1:3.000 aprox.

Evolución de usos del suelo en la zona hornera del Barranco del Hornillo, 2016, Santa Ana la Real | fuente Ortografía Aérea del Plan Nacional. 2016. Instituto Geográfico Nacional. Tomada a escala 1:3.000 aprox.

9

Entre 1999 y 2019 se han sucedido graves incendios forestales en antiguas zonas caleras de Alájar, Almonaster la Real, Castaño del Robledo y Santa Ana la Real que han obligado incluso a evacuar a las tres últimas poblaciones. 


\section{Arquitectura vernácula y otros usos productivos y estéticos}

Durante siglos, la cal viva elaborada por los caleros constituyó el único conglomerado utilizado para unir los mampuestos o los ladrillos para la construcción de los paramentos, reforzar los muros de tapial o asegurar las tejas voladas de las cubiertas. La argamasa elaborada con el carbonato cálcico (cal morena) contribuyó a dibujar en la arquitectura de toda la comarca, tanto en los edificios monumentales como en la obra pública, un estilo particular, originando un paisaje urbano que hoy calificamos como vernáculo.

El uso de la argamasa ha influido en los sistemas constructivos, como la mampostería careada, al menos hasta la primera planta de las casas, lo que representa una solución tradicional muy eficiente para evitar humedades. También ha estado presente en las construcciones e infraestructuras rurales, como revestimiento de las acequias y albercas, o para consolidar los muros de tapial. Por otro lado, el enlucido con cal blanca ha dotado de otro rasgo distintivo a la arquitectura serrana, manifestada con la riqueza de texturas y matices que aporta a los muros, paredes y fachadas, rasgo compartido como es sabido con otros territorios vecinos de Andalucía.

Sin duda, la huella de la cal y la piedra caliza ha marcado la fisonomía del paisaje serrano. Como materia prima, la cal ha sido fundamental para el desarrollo de actividades artesanales y semi-industriales serranas (alfarerías de Cortegana, hornos de ladrillo de Aroche, Cala y Cumbres Mayores y curtido de pieles en las tenerías de Almonaster la Real y Aracena). Como elemento ornamental su presencia es visible en los empedrados decorati-

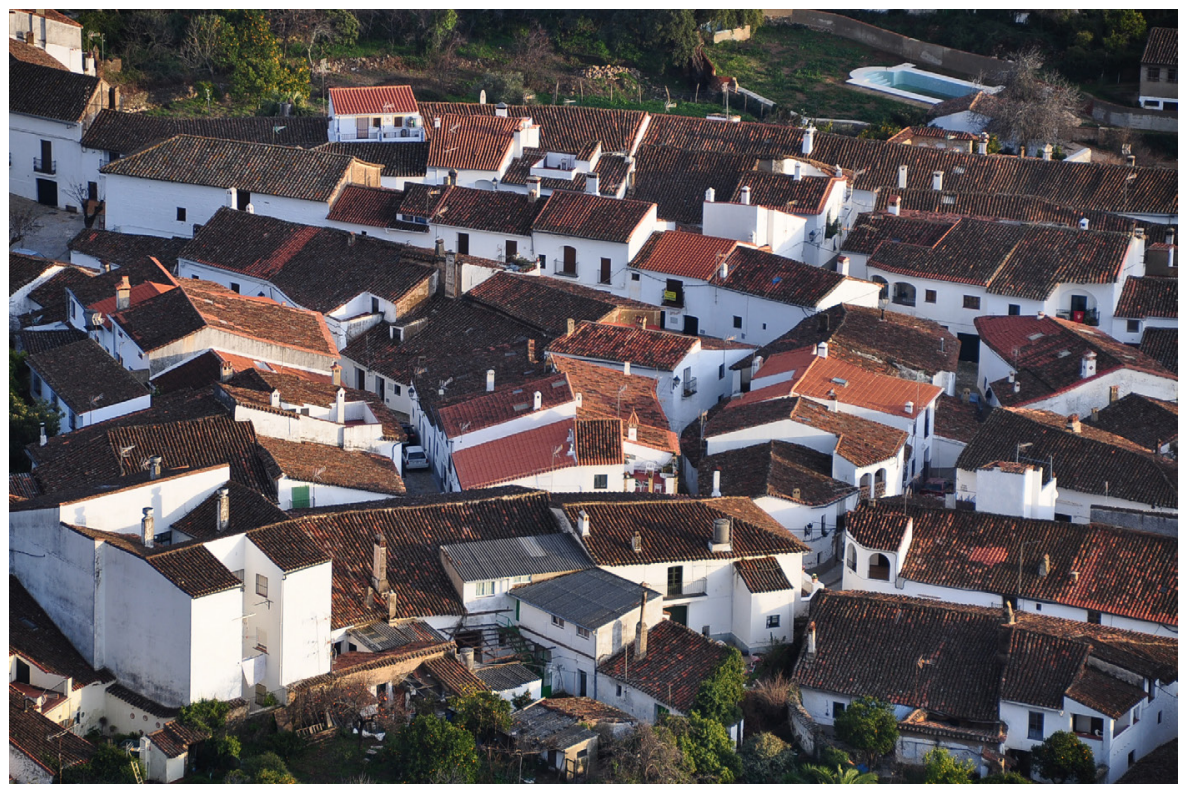



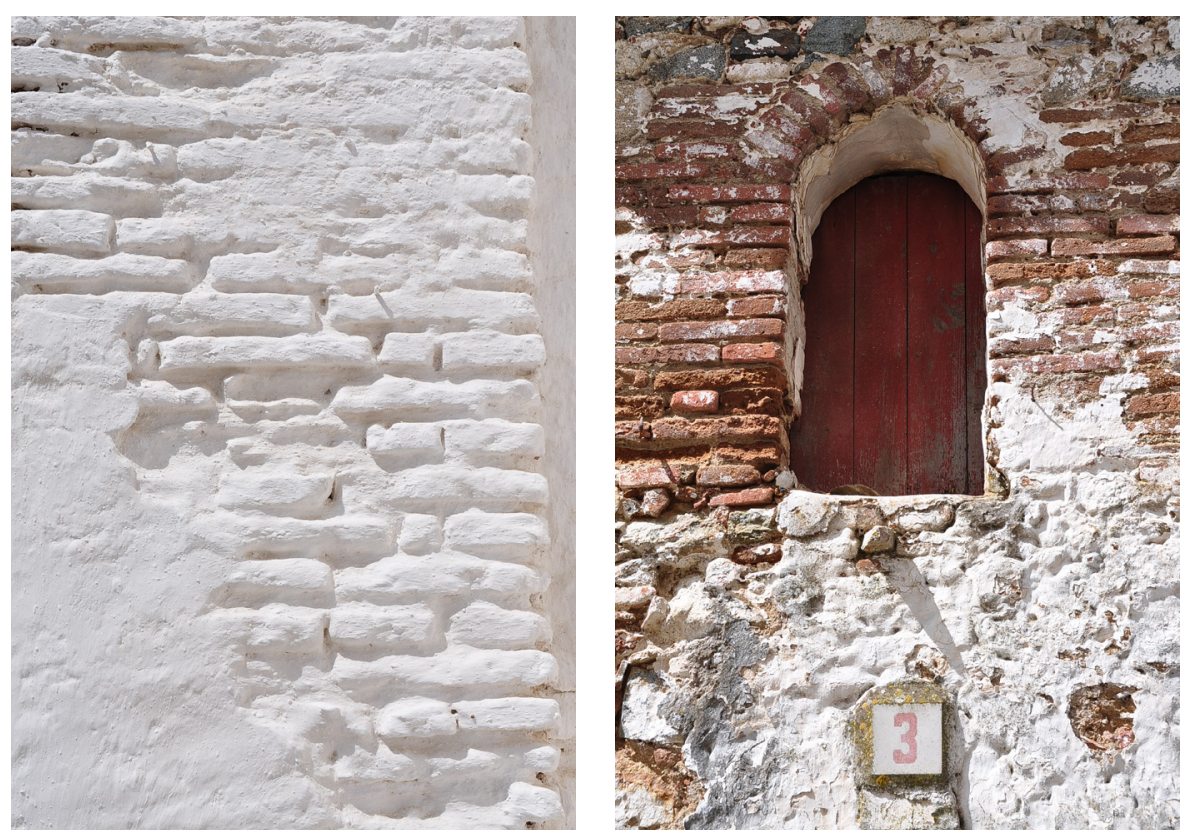

vos o sobre aquellos muros donde podía contrastar, como los de tapial o ladrillo, o como instrumento de la expresión escrita en paredes, lógicamente teñida. Llama la atención cómo algunas de estas manifestaciones han pervivido durante generaciones, representando hitos cargados de simbolismo en el imaginario colectivo, como por ejemplo, el texto "el camino de todos" que se rotula en los paredones próximos al cementerio de Linares de la Sierra.

\section{DISCUSIÓN Y CONSIDERACIONES FINALES}

La estrecha vinculación de la producción de cal con unas formas de vida tradicionales vigentes durante siglos convierte al conjunto de los hornos, a la propia actividad y a los conocimientos técnicos que la sustentan en destacados exponentes del patrimonio etnológico.

Como estructuras físicas, los hornos son las huellas materiales de una actividad de transformación de carácter preindustrial característica de la comarca. Junto con las almazaras, los molinos hidráulicos, las eras, las tenerías, los hornos panaderos, los lagares y las fábricas de harina, luz y corcho..., los de cal constituyen un patrimonio cultural relevante; pero, tristemente, uno de los menos protegidos y valorados de todo el Parque Natural (Fajardo de la Fuente, Tarín Alcalá-Zamora y Marín Gallardo 2004). Al mismo tiempo, los saberes tradicionales acumulados durante siglos, que han servido para el manejo del monte, el aprovisionamiento del combustible, la extracción de la roca caliza, las labores de montaje y calcinación y las técnicas para la elabo-

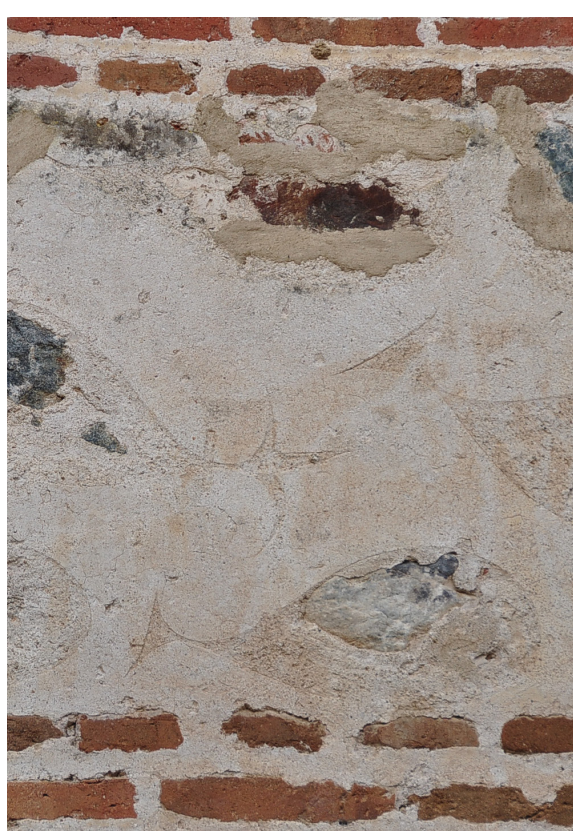

La cal, presente en la epidermis de la arquitectura vernácula (2014) | fotos Amalia Tarín Alcalá-Zamora 

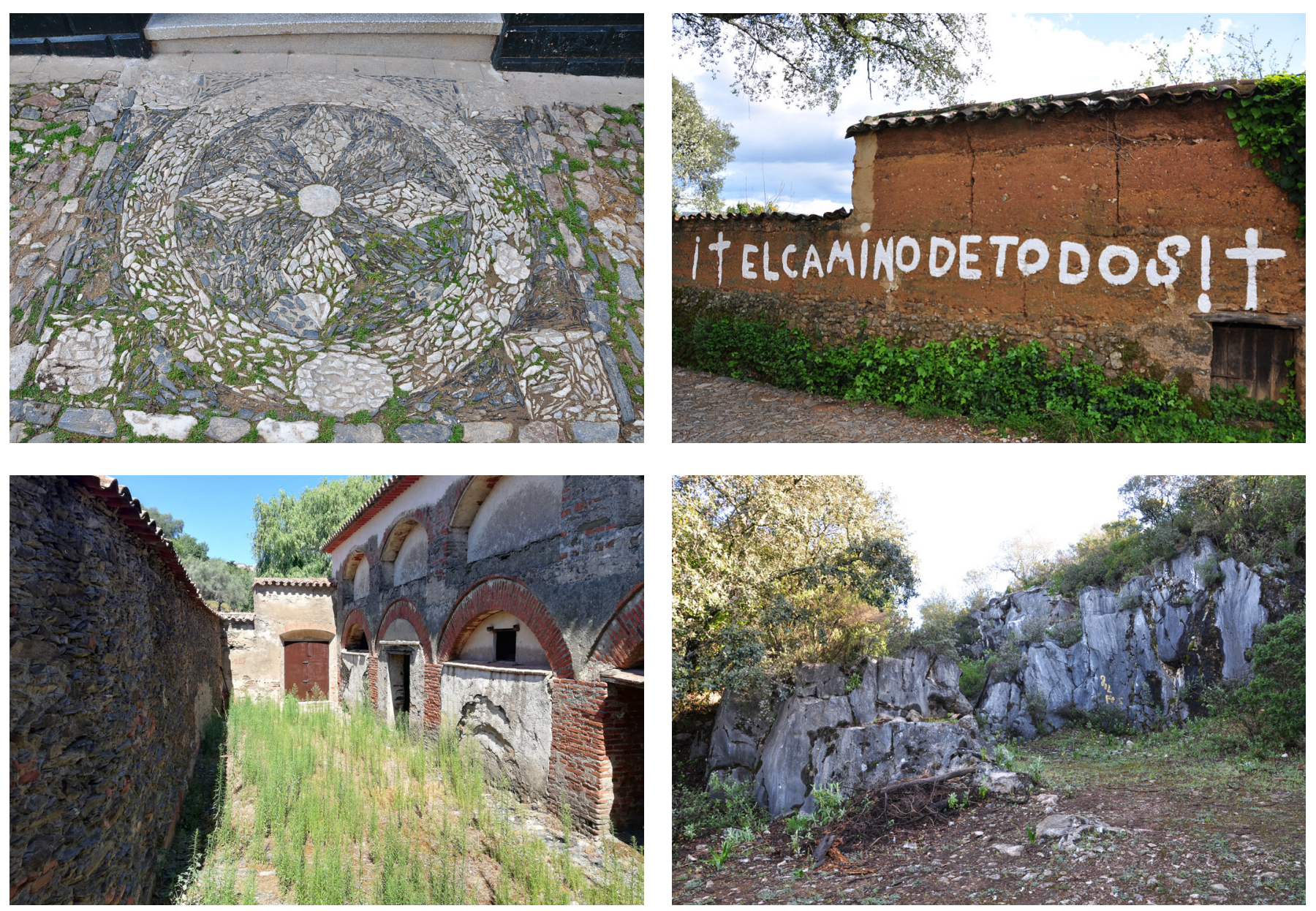

Otras manifestaciones del uso de la piedra caliza: empedrado decorativo y expresión escrita (Linares de la Sierra), curtiduría (Almonaster la Real) y pedrera (Alájar) (2014) | fotos Amalia Tarín AlcaláZamora

ración de morteros y enjalbegados, constituyen un componente fundamental de este patrimonio.

Esta riqueza etnológica atesora, además, un valor simbólico que no puede pasar desapercibido: los hornos son los restos de unas actividades periclitadas, pero que forman parte de un pasado muy reciente que está presente en la memoria de muchos de los vecinos de la sierra. Las instalaciones aún en pie actúan como elementos simbólicos que conectan el pasado con el presente y dan sentido de continuidad histórica a la población. Por su parte, los conocimientos de la actividad subrayan aún más este valor representativo, pues son los antiguos caleros los depositarios de esta memoria viva. Por todo ello, la catalogación y restauración de los hornos, así como la valorización de los saberes tradicionales podrían contribuir al conocimiento de la historia local y al reforzamiento de la identificación colectiva del vecindario con sus municipios y con la comarca. Concebido de esta manera integral, el oficio calero es patrimonio histórico a la vez que etnológico, por cuanto la 
memoria de la actividad es imprescindible para el conocimiento de la historia de la comarca, al tiempo que un marcador de la identidad de la sociedad serrana.

Pero este patrimonio no es sólo un vestigio de tiempos pasados, sino que cuenta con un enorme potencial para el presente y el futuro. La valorización de la cultura de la cal puede funcionar como un motor de iniciativas de gran calado. No se trata solo del inventario y la restauración de las instalaciones horneras para su disfrute, lo cual es muy relevante, sino de impulsar actuaciones más audaces que revitalicen la actividad con proyección futura.

Son muchas las iniciativas posibles. Concluimos apuntando sucintamente dos estrategias cuya potencialidad es a nuestro juicio muy elevada. En primer lugar, el rescate de los saberes tradicionales caleros a través de un programa de fomento de la transmisión del oficio. Este proyecto permitiría salvaguardar el conjunto de conocimientos profesionales que se conserva en la memoria de los caleros vivos, pero con un sentido práctico o utilitario. La creación de escuelas taller o casas de oficios con la participación de los viejos caleros podría garantizar la continuidad del oficio en la comarca a través de la formación profesional. Los nuevos empleos se orientarían a la producción de cal como materia prima destinada a la rehabilitación y restauración de viviendas, monumentos e infraestructuras tradicionales conforme a los patrones constructivos vernáculos, pero también para la edificación bioclimática más innovadora. Esta iniciativa aseguraría el mantenimiento del parque arquitectónico que históricamente ha singularizado a la sierra, al tiempo que diversificaría la producción de cal hacia otros mercados que se han revelado muy competitivos, ya que el uso de la cal es de plena actualidad en restauración y en la construcción sostenible por sus notables cualidades frente al uso de aglomerantes y pinturas sintéticas industriales (Martín et ál. 1998; Robador González 1999) ${ }^{10}$. Paralelamente, el aprovechamiento sostenible de los recursos forestales como combustible para hornadas, así como de la extracción de la materia prima en canteras y pedreras supondrían una impagable contribución a la limpieza del monte y a su regeneración, aminorando el riesgo de incendios forestales.

La segunda estrategia consiste en el impulso de iniciativas dirigidas a la difusión del patrimonio calero y la puesta en marcha de un modelo turístico sostenible de base comarcal. Destacaría la creación de centros de interpretación, que hicieran legible a los distintos sectores de población (nativa y visitante) todo el legado cultural que representa la actividad hornera. En este sentido, experiencias como la del Museo de la Cal de Morón de la Frontera (Sevilla) han mostrado muy buenos resultados en la valorización de la cal, lo cual fue reconocido por la propia UNESCO en 2011 inscribiendo esta actividad en el Registro de Buenas Prácticas de Salvaguardia del Patrimonio Cultural Inmaterial de la Humanidad.
10

Son muchas las ventajas de la cal prieta frente a los cementos industriales. Destacamos las siguientes: compatibilidad con variedad de materiales, porosidad, resistencia a la humedad y función aislante térmica y acústica. Por su parte, la cal blanca posee también cualidades extraordinarias (higiénicas, inodoras, decorativas y protectoras). 


\section{Informantes}

Alájar: Asunción González López y Julio

\section{García González}

Almonaster la Real: Federico Castilla

Aracena: Eduardo Romero Bomba

Aroche: Antonio Rodríguez Guillén

Cala: Timoteo Ribera

Cañaveral de León: Joaquín Hernández

de la Obra, Pilar Aycart y Julián

Sánchez Rubio

Fuenteheridos: Guillermo Carballo y

Jose Luis Macías

Jabugo: Pablo Romero

Santa Ana la Real: Eloy Martín, Isidro

Martín, Onofre López, Víctor Martín,

Amelia Martín y Blas López
Paralelamente, el diseño de itinerarios o rutas de la cal que discurran por el entorno serrano tomando los hornos como hitos del camino completaría esta estrategia, amplificando sus efectos. Las rutas exigirían la mejora de las vías pecuarias y caminos públicos, es decir, la restauración de muros de piedra seca y tapiales y la recuperación del sistema del desagüe, de los empedrados, porteras, lievas y casas de labor, así como la adecuación del entorno de los hornos y la consolidación de las instalaciones. La materialización de esta propuesta daría a conocer in situ la integración de los hornos en el ecosistema serrano y la riqueza del sistema agro-silvo-pastoril propio de la dehesa en cuya conformación la actividad calera ha intervenido directamente.

Vistos de esta manera, los centros de interpretación en paralelo con las rutas se conciben como instrumentos pedagógicos de acercamiento de la población (autóctona y turista) al ecosistema serrano, haciendo comprensible la diversidad de elementos de distinta naturaleza existentes en el territorio y transmitiendo el mensaje de la sostenibilidad como hilo conductor de todo el recorrido. Esta interpretación supone una mirada contemporánea al pasado, que lo hace inteligible a los visitantes y contiene enseñanzas implícitas sobre la posibilidad de establecer relaciones armónicas del ser humano con el medio ambiente.

El carácter holístico y singular de la cultura calera es, por tanto, una oportunidad para promover una oferta turística diferenciada en el entorno del Parque Natural y desencadenar una espiral de actividades que dinamicen la economía, siempre y cuando sean los propios vecinos los gestores de los recursos y los principales beneficiarios de su desarrollo.

En definitiva, con este trabajo hemos pretendido dar a conocer los valores patrimoniales de una actividad característica del pasado, pero también su potencialidad como recurso para la dinamización social y económica. De este modo la revitalización de la tradición, lejos de ser una acción testimonial, se convierte en instrumento de futuro. 


\section{BIBLIOGRAFÍA}

- Carrero Carrero, A.J. (1995) Santa Ana la Real. En: Márquez Domínguez, J.A. y Jurado Almonte, J.M. (coord.) Los pueblos de Huelva, vol. 4. Huelva: Huelva Información, pp. 1117-1132

- Carrero Carrero, A.J. (1997) Las rocas ornamentales. El granito de Santa Olalla de Cala. En: Márquez Domínguez, J.A. y Jurado Almonte, J.M. (coord.) Artes, Costumbres y Riquezas de la provincia de Huelva, vol. 4. Huelva: Huelva Información, pp.1117-1132

- Collier, J.F. (2009) Del deber al deseo. Recreando familias en un pueblo andaluz. México: CIESAS-UAM-UI

- Díaz-Aguilar, A.L. (2012) Carta Etnológica del Término Municipal de Almonaster la Real (Huelva). Sevilla: Dirección General de Bienes Culturales. Consejería de Cultura. Junta de Andalucía

- Garrido Morillo, R. y Romero Macías, E. (2004) La potencialidad turística del patrimonio geológico y minero del parque natural Sierra de Aracena y Picos de Aroche (Huelva. España). Pasos: revista de turismo y patrimonio cultural, vol. 2, pp. 215-232. Disponible en línea: http://mail. pasosonline.org/Publicados/2204/PS050204.pdf [Consulta: 24/11/2020]

- Fajardo de la Fuente, A. y Tarín Alcalá-Zamora, A. (1999) El patrimonio en la Sierra de Huelva: un recurso amenazado a corto plazo. En: Hernández Pi, B. (coord.) XIV Jornadas de Patrimonio en la Sierra de Huelva. Huelva: Diputación Provincial, pp. 219-240

- Fajardo de la Fuente, A., Tarín Alcalá-Zamora, A. y Marín Gallardo, M. A. (2004) Sierra de Aracena y Picos de Aroche. Recorrido natural y cultural. Sevilla: Edición de los autores

- Hernández-Ramírez, J. (2005) Activando la memoria, mirando al futuro. Patrimonialización de un oficio perdido y dinamización turística. En: Pascual-Fernández, J.J. y Florido, D. (coord.) ¿Protegiendo los recursos? Áreas protegidas, poblaciones locales y sostenibilidad. Sevilla: Asociación Andaluza de Antropología, pp. 173-186

- Hernández-Ramírez, J. (2007) Viejos y nuevos usos de la arquitectura industrial vernácula. Patrimonialización y turismo en Santa Ana la Real (Huelva). En: Aranda Bernal, A.M. (coord.) Arquitectura vernácula en el mundo Ibérico. Sevilla: Universidad Pablo de Olavide, pp. 332-339

- Hernández-Ramírez, J. (2011) Tiempo de hornadas. Etnografía de la actividad calera en Santa Ana la Real. Huelva: Diputación Provincial

- Herrero Núñez, E. (2005) La cal hoy: fabricación, tipos de cal, especificaciones de calidad, normas y criterios de conformidad. Revista Cemento-Hormigón, n. ${ }^{\circ} 874$, pp.1019

- Instituto de Estadística y Cartografía de Andalucía (2020) Nomenclátor Geográfico de Andalucía. En:
Buscador de nombres geográficos. Disponible en: http:// www.ideandalucia.es/nomenclator/ [Consulta: 01/12/2020]

- Instituto Geográfico Estadístico (1899) Santa Ana la Real. En: Bosquejo planimétrico por términos municipales, escala 1:25.000

- Instituto Geográfico Nacional. Centro Nacional de Información Geográfica (2020) Fototeca Digital. Disponible en: http://fototeca.cnig.es/ [Consulta: 01/12/2020]

- Instituto Geográfico Nacional. Centro Nacional de Información Geográfica (2020) Hojas 874 (1946), 895 (1946), 896 (1951), 897 (1955), 915 (1948), 916 (1950), 917 (1955), 918 (1949), 919 (1918), 937 (1949), 938 (1951), y 939 (1951). En: Mapa Topográfico Nacional 1:50.000. Disponible en: https://www.ign.es/web/cbg-area-cartografia [Consulta: 01/12/2020]

- Lijó, P.M. y Monge Manso, J. (1999) Notas para el estudio de los hornos de Cal de Santa Ana la Real. En: XIV Jornadas de Patrimonio Histórico de la Comarca de la Sierra. Huelva: Diputación Provincial, pp. 147-166

- Madoz, P. (1845-1850) Diccionario geográficoestadístico-histórico de España y sus posesiones de Ultramar. Madrid: Imp. del Diccionario

- Martín, M., Azconegui Morán, F. y García y Conesa, O. (1998) Guía práctica de la cal y el estuco. León: Editorial de los Oficios

- Ministerio de Cultura y Deporte (2020) Respuestas generales-Interrogatorio. En: Catastro de Ensenada. Disponible en: http://pares.mcu.es/Catastro/servlets/ ServletController?accion=2\&opcion=30 [Consulta: 26/11/ 2020]

- Monge Manso, J. (2007) Santaneros. Identidad y comunidad en Santa Ana la Real (Huelva). Huelva: Diputación Provincial

- Monge Manso, J. (2005) Análisis cronotópico de la identidad cultural. Huelva en su Historia, vol. 12, pp. 185206

- Núñez Laso de la Vega, J.M. (1999) Minería y poblamiento en la Sierra de Huelva. En: Hernández Pi, B. (coord.) XIV Jornadas de Patrimonio en la Sierra de Huelva. Huelva: Diputación Provincial, pp. 83-134

- Robador González, M.D. (1999) Cal y arquitectura. Tesis doctoral inédita, Universidad de Sevilla

- Ruiz González, J.E. (1999) Huelva, según las relaciones enviadas por los párrocos al geógrafo real Tomás López en el siglo XVIII. Huelva: Diputación Provincial 